\title{
On the Threshold Friction Velocity for Saltation of Sand
}

\author{
by
}

\author{
Shigeru Nemoto, Mitsuo Mitsudera, Katsumi Takahashi, \\ Hiroshi Uotsu and Setsuko Kobayashi
}

Meteorological Research Institute, Tokyo

(Received September 25, 1969)

\begin{abstract}
It is first examined whether the experimental results in a wind tunnel on the saltation of sand which have been published hitherto by several research workers will hold or not in field observation. Secondly, simple and practical methods to estimate a threshold friction velocity for saltation in field observation are suggested.
\end{abstract}

\section{Introduction}

We carried out a survey from a meteorological point of view, in order to obtain some fundamental data for an effective disposition of trees to arrest sand shifting over reclaimed ground at the littoral industrial districts in Keiyo, a convenient name for the region extending from Tokyo to Chiba. The main points aimed at in the survey were as follows:

a) to examine the effect of trees in arresting the drifting of sand,

b) to determine the threshold friction velocity for sand movement and to estimate the amount of sand movement,

c) to survey the winds around the littoral industrial districts in Keiyo.

In the present paper, we deal with the following two problems in relation to item b):

1) to examine whether the theoretical and wind-tunnel experimental results on the saltation of sand which have been obtained hitherto by various authors will also hold or not in field observation,

2) to suggest practical methods to estimate a threshold friction velocity for saltation of sand in field observation.

Sand movements due to wind have been grouped into the following three classes,

1) suspension,

2) saltation,

3) surface creep.

These have been confirmed by the observations of BAGNoLd $(1936,1937,1938)$ and ChePIL (1945).

1) Suspension

This is mainly the motion of fine sand grains with diameters of less than 0.1 $0.05 \mathrm{~mm}$, with flying paths almost horizontal and flying distances longer. Their flying height reaches several meters in moderate wind. 


\section{2) Saltation}

This is mainly the motion of sand grains with diameters of $0.2-0.3 \mathrm{~mm}$. It has been theoretically dealt with by KAWAMURA (1948) and experimentally in a wind tunnel by BELLY (1964). This motion is limited within a layer several tens of centimeters at most from the sand surface and scarecely affected by turbulence (KAwAMURA). A large part of sand movement is accounted for by shifting due to saltation.

\section{3) Surface creep}

This is the sliding motion of sand grains-especially, of comparatively large ones-on the sand surface. The amount of sand moving in this way has been found by BAGNOLD to be $1 / 4$ of that due to saltation.

The size distribution of sand grains is similar wherever the sand moves violently and dunes grow up rapidly. The greater part of the sand there is sand grains with diameters about 0.2 or $0.3 \mathrm{~mm}$, those with diameters smaller than $0.05 \mathrm{~mm}$ or larger than $0.5 \mathrm{~mm}$ being very scarce. The sand which has such a size distribution has usually been called dune sand. So far as dune sand is concerned, it seems reasonable to assume that the sand surface is composed of sand grains with a uniform diameter of about $0.25 \mathrm{~mm}$. KAWAMHRA dealt theoretically with the saltation of dune sand. BELLy also dealt mainly with dune sand in a wind tunnel experiment.

In the first place, we want to review briefly the main theoretical and experimental results thus far obtained by these investigators.

\section{Theoretical treatment}

The main results of the theoretical treatment by KAWAMURA basic for our discussion will be summarized in the following.

\subsection{Threshold friction velocity for saltation of sand $\left(u_{* t}\right)$}

KAWAMURA has suggested the following expression about a threshold friction velocity for saltation of sand,

$$
u_{* t}=\pi^{1 / 6}(6 \lambda)^{1 / 3}\left(\tan \varphi_{0}\right)^{1 / 2} \sqrt{\frac{\sigma}{\rho} g d}
$$

on the basis of the consideration that the shearing stress $\left(\rho u_{*}{ }^{2}\right)$ working on a unit area of sand surface is equal to the drag force to sand grains which have jutted out over the sand surface. In this expression

$\lambda$ : a net volume of sand grains contained in the unit volume near the sand surface,

$\varphi_{0}:$ a static friction angle on the sand surface,

$\sigma:$ density of sand grains,

$\rho:$ density of the air,

$g:$ the acceleration of gravity,

$d$ : mean grain diameter of sand,

but the buoyancy force of the air has been here left out of consideration. When it is taken into consideration, the above expression becomes similar in form as the empirical formula of BAGNOLD which will be described later. 


\subsection{Stationary drift sand}

It may be considered that there is an automatic adjusting process between wind velocity and amount of sand shifting, and that wind velocity takes a constant value at a level very close to the sand surface independent of wind velocity, that is, a focus of wind profile is found there. It may also be considered that in the case of average stationary drift sand the velocity of the wind very close to the sand surface is always kept at a value at which sand grains start to move. Therefore, the amount of sand shifting saturates for a certain wind velocity.

\subsection{Vertical distribution of amounts of sand transport (stationary state)}

Mass of sands which flow vertically across a unit length per unit time may be expressed by

$$
q(z)=2 m \cdot n_{0} \frac{\beta U^{\prime}}{g} \exp \left[-\frac{1}{\pi} \frac{z}{h_{0}}\right]
$$

accordig to KAWAMURA, where

$m$ : mass of a sand grain,

$n_{0}$ : number of sand grains which jump out from a unit area of the sand surface per unit time,

$U^{\prime}$ : wind velocity at the focus,

$z:$ height from the sand surface,

$h_{0}$ : a mean value of $h$,

$h$ : maximum height in a flying path,

$$
\beta=\alpha / m, \quad \alpha=3 \pi \mu d \quad \text { (Stokes law) }
$$

\section{Experiment in the wind tunnel}

In the present chapter, the main results of experiments in the wind tunnel which have been made by BAGNOLD and ZINGG will be summarized.

\subsection{Threshold friction velocity for saltation of sand $\left(u_{* t}\right)$}

BAGNOLD (1954) has proposed the following empirical formula for the threshold friction velocity for saltation of sand

$$
u_{* t}=A \sqrt{\frac{\sigma-\rho}{\rho} g d}
$$

where $A$ is a proportional constant and takes a constant value 0.08 for large sand grains.

\subsection{Stationary drift sand}

Plotted on semi-logarithmic paper, the vertical distributions of wind velocity remain straight lines, and they all meet at a certain point close to the sand surface, which is called "a focus" by BAGNOLD. When the height of the focus and the wind velocity there are denoted by $z^{\prime}$ and $U^{\prime}$, respectively, the following relations have been 
obtained among $z^{\prime}, U^{\prime}$ and $d$, by ZINGG (1952):

$$
\begin{array}{ll}
z^{\prime}=10 \mathrm{~d} & (\mathrm{~mm}) \\
U^{\prime}=9 \mathrm{~d} & (\mathrm{~m} / \mathrm{sec})
\end{array}
$$

(d denotes the mean grain size of sand in $\mathrm{mm}$ ) and then the empirical formula

$$
U=5.75 u_{* t} \log \frac{z}{z^{\prime}}+U^{\prime}
$$

holds for layers higher than $z^{\prime}$.

\subsection{Vertical distribution of the amount of sand transport}

Vertical distributions of the amount of sand transport have been obtained by capturing sand grains with traps, but only a few experiments have been made.

\subsection{Relation between wind velocity and rate of sand transport}

BAGNOLD (1954) has proposed the following empirical formula for the relation between friction velocity $u_{*}$ and rate of sand movement per unit width and unit time $Q$,

$$
Q=C \sqrt{\frac{d}{D}} \frac{\rho}{g} u_{*}^{3}
$$

where

$D$ : the grain diameter of the standard $0.25 \mathrm{~mm}$ sand,

$d:$ the grain diameter of the sand in question,

$u_{*}$ : friction velocity,

$C$ : empirical constant, taking the following values:

i) 1.5 for a nearly uniform sand,

ii) 1.8 for a naturally graded sand,

iii) 2.8 for a sand with a very wide range of grain sizes.

Besides BAGNOLD's formula mentioned above, two or three empirical formulas estimating the rate of sand transport have been proposed, and even BAGNoLD's formula contain some doubtful points.

It will be see from the foregoing description that, though there are various points not yet fully elucidated, the means of estimating $u_{* t}$ and $Q$ which we want to take up here have already been proposed both theoretically and experimentally. But it seems that examples of actual application of these results in the field observation are few, apart from BAGNOLD's observation in a desert in Egypt in 1938.

Hence, we have tried to apply these results to our observation at Anegasaki in order to check their applicability in field observation.

It must be examined whether the following conditions have been satisfied or not before applying these results:

i) turbulence need not be considered, 
ii) the state of the sand surface is comparatively smooth and the scale or phenomenon is of the same order as that of the experiments in the wind tunnel,

iii) the water content in the layer very close to the sand surface is $0 \%$,

iv) the effect of stability of the air layer is negligibly small,

v) the mean grain size of the sand is around $0.25 \mathrm{~mm}$.

Since the above conditions may be considered to be almost satisfied for both the sand surface and the layer up to several tens of centimeters from the sand surface in our observation at Anegasaki, then the relations which have been obtained from the wind tunnel experiments may also be considered to be applicable to our field observation. Therefore, we estimated $u_{*: t}, z_{0}, z^{\prime}$ and $U^{\prime}$ and examined the relation between $U_{30}$ (wind velocity at a height of $30 \mathrm{~cm}$ from the sand surface) and $u_{*}$ by using the data observed at Anegasaki.

\section{Item and method of observation}

\subsection{Wind profiles above the sand surface}

A small three-cup anemometer was used for the measurement of horizental mean wind velocity. Ten such anemometers were mounted respectively at the height of 0.2 , $0.3,0.4,0.5,0.7,1.0,1.5,2.0,3.5,6.0 \mathrm{~m}$ on a pole $6 \mathrm{~m}$ high, and then both the number of rotations of each anemometer and yes-or-no signs of sand movement around there, which were observed with the naked eye, were automatically simultaneously photographed with a $16 \mathrm{~mm}$ cine-camera.

\subsection{Temperature profiles above the sand surface}

The self-recording mercury thermometer was used for the measurement of air temperature. Six thermometers of this type were mounted respectively at the height of $0.2,0.4,0.9,1.9,3.9,5.9 \mathrm{~m}$ on another pole $6 \mathrm{~m}$ high (each thermometer was covered

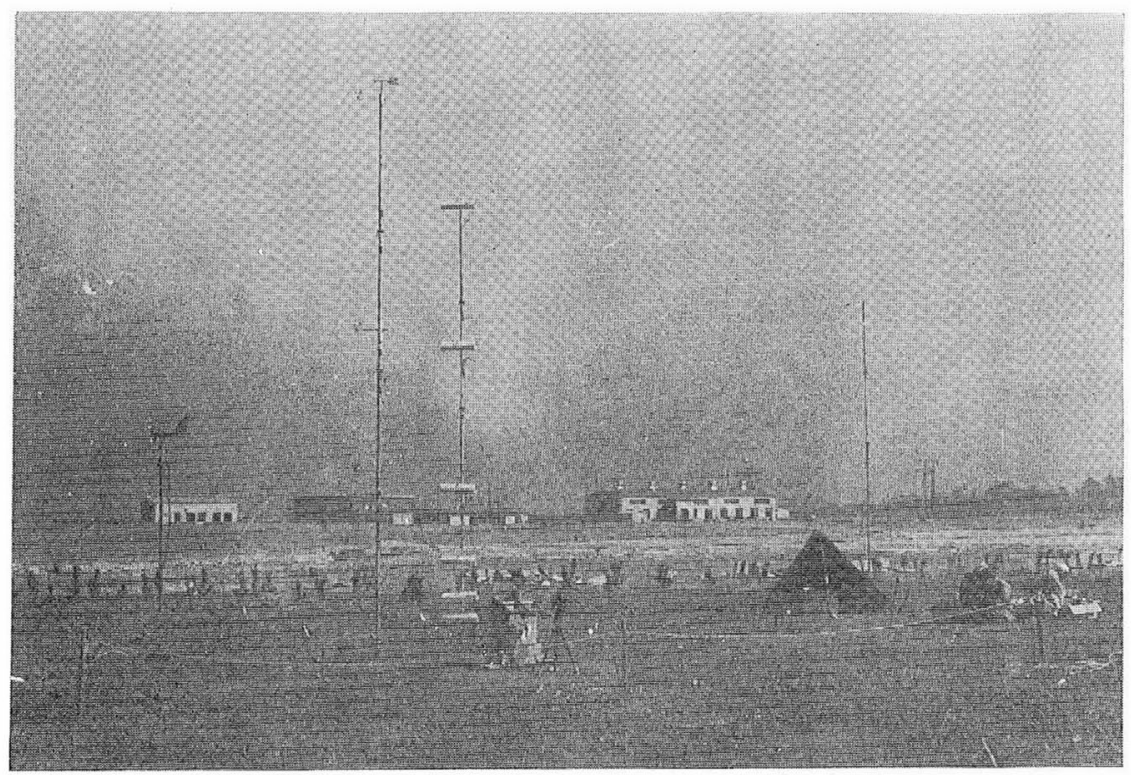

Fig. 1. General view of observation site and disposition of instruments. 
with a cylindrical shelter which protects it from solar radiation) and then the temperature at each height was recorded with a recording millivoltmeter.

\subsection{Water content of the sand and grain size distribution close to the sand surface}

We gathered sand near the sand surface with sampling cups during the observation, and estimated the water content of the sand from the difference of weight before and after drying and also measured grain size distribution.

\subsection{Vertical distribution of the amount of sand transport}

We stuck sand grains on a vinyl tape $18 \mathrm{~mm}$ wide which was stretched from the sand surface to the top of a pole $6 \mathrm{~m}$ high, and measured photo-electrically the amount of sand which had adhered to it.

The disposition of the observation instruments on the spot is as shown in Fig. 1. The general wind direction and velocity at the observation site were observed with an aerovane at a height of $2.8 \mathrm{~m}$.

\section{Results}

In this chapter, the results of observation at Anegasaki and their analyses will be described.

\subsection{Mean grain size of sand}

The mean grain size of sand obtained from the grain size distribution of the sand which was sampled on the sand surface was $0.25 \mathrm{~mm}$. The sand at the observation site was dune sand. This value will be adopted for various estimations in the following.

\subsection{Vertical distribution of the amount of sand transport}

We moved a vinyl tape $18 \mathrm{~mm}$ wide and $6 \mathrm{~m}$ long on which sand grains had stuck by exposing it about an hour through on a slit of $16 \mathrm{~mm} \times 3 \mathrm{~mm}$ under a light with constant intensity, and measured the intensity of its transparent light with the illuminometer (No. 5 type Toshiba illuminometer).

It may be considered that the rate of light absorption due to the sand which stuck on the vinyl tape will be approximately proportional to the amount of sand that on, $q(z)$. The vertical distribution of $q(z)$ estimated in this way is shown in Fig. 2. The figure on the right hand side in Fig. 2 shows one on a scale magnified in the direction of height. It will be found from this figure that there is a linear relation between $\log q(z)$ and $z$ to a height of about $22 \mathrm{~cm}$.

On the other hand, according to KAWAMURA's theory $q(z)$ is expressed as

$$
q(z)=2 m n_{0} \frac{\beta U^{\prime \prime}}{g} \exp \left[-\frac{1}{\pi} \cdot \frac{z}{h_{0}}\right]
$$



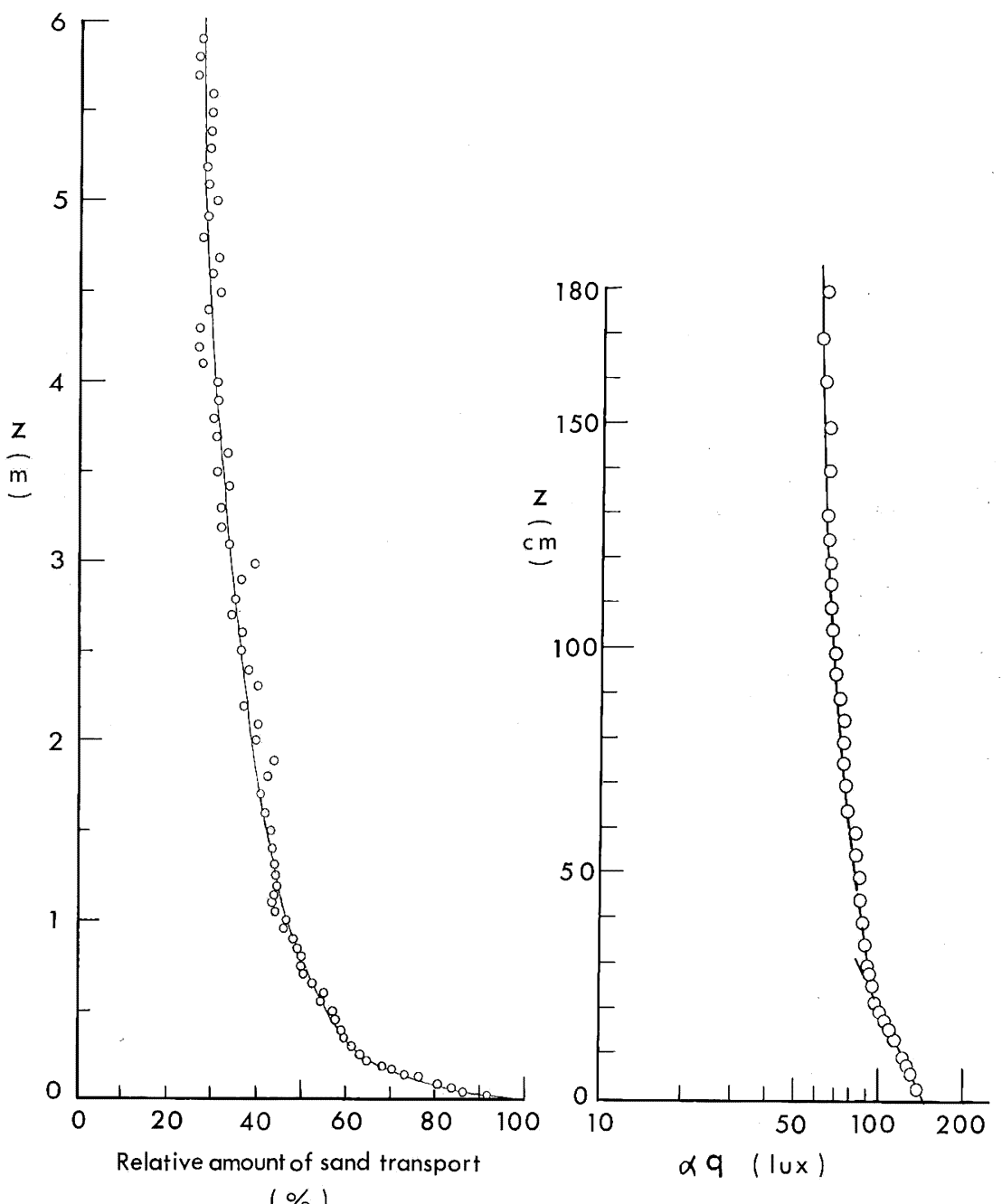

Fig. 2. Vertical distribution of the amount of sand transport. The figure on the left hand side shows the relative amount of sand transport at each height to that on the sand surface. In the figure on the right hand side $q$ is assumed proportional to the intensity of transparent light.

as mentioned above and this means that there is a linear relation between $\log q(z)$ and $z$, and it may be considered from actual observation in the field that this relation can be applied to a height of about $22 \mathrm{~cm}$. As $z$ increases, the value of $q(z)$ observed in the field becomes larger than that obtained theoretically. This may be considered to be due to the fact that $h$ is assumed to be small and $U^{\prime}$ to be independent of $z$. Since sand grains with large $h$ fly in the layer where the wind velocity is larger, the mean speed of sand grains is large, hence it is natural that the amount of sand transport at a higher level is larger than that estimated theroretically. Furthermore, microscopic photographs which show the adhesion state of sand grains at each height are shown in Figs. 3-7. The time of exposure of this vinyl tape was one hour. 


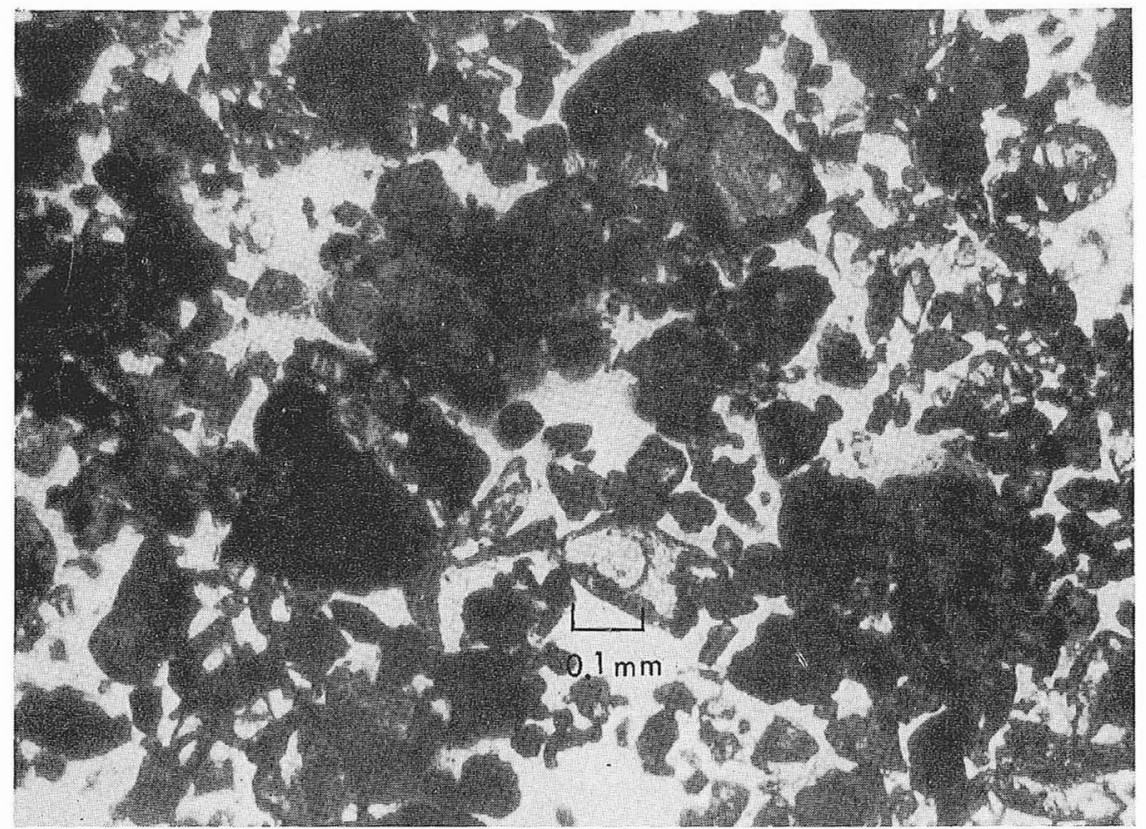

Fig. 3. Microscopic photograph of sand stuck on a vinyl tape. $z=10 \mathrm{~cm}$.

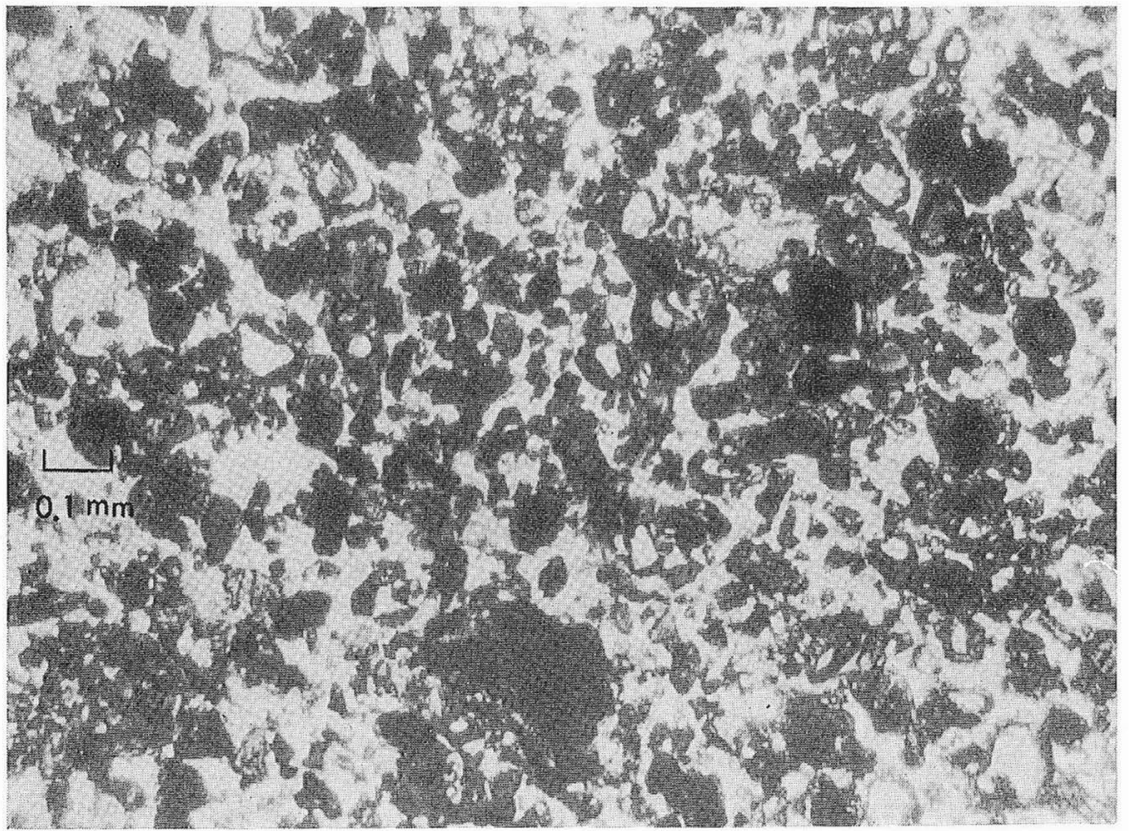

Fig. 4. Microscopic photograph of sand stuck on a vinyl tape. $z=30 \mathrm{~cm}$. 


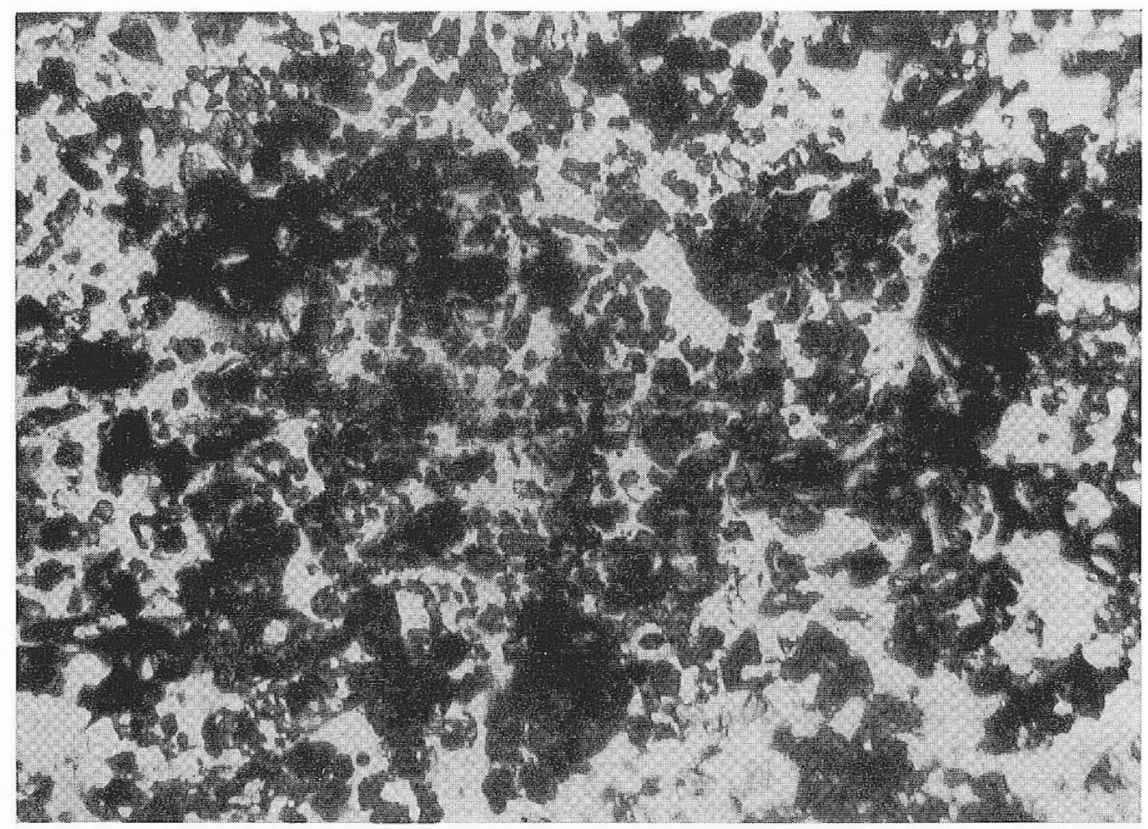

Fig. 5. Microscopic photograph of sand stuck on a vinyl tape. $z=50 \mathrm{~cm}$.

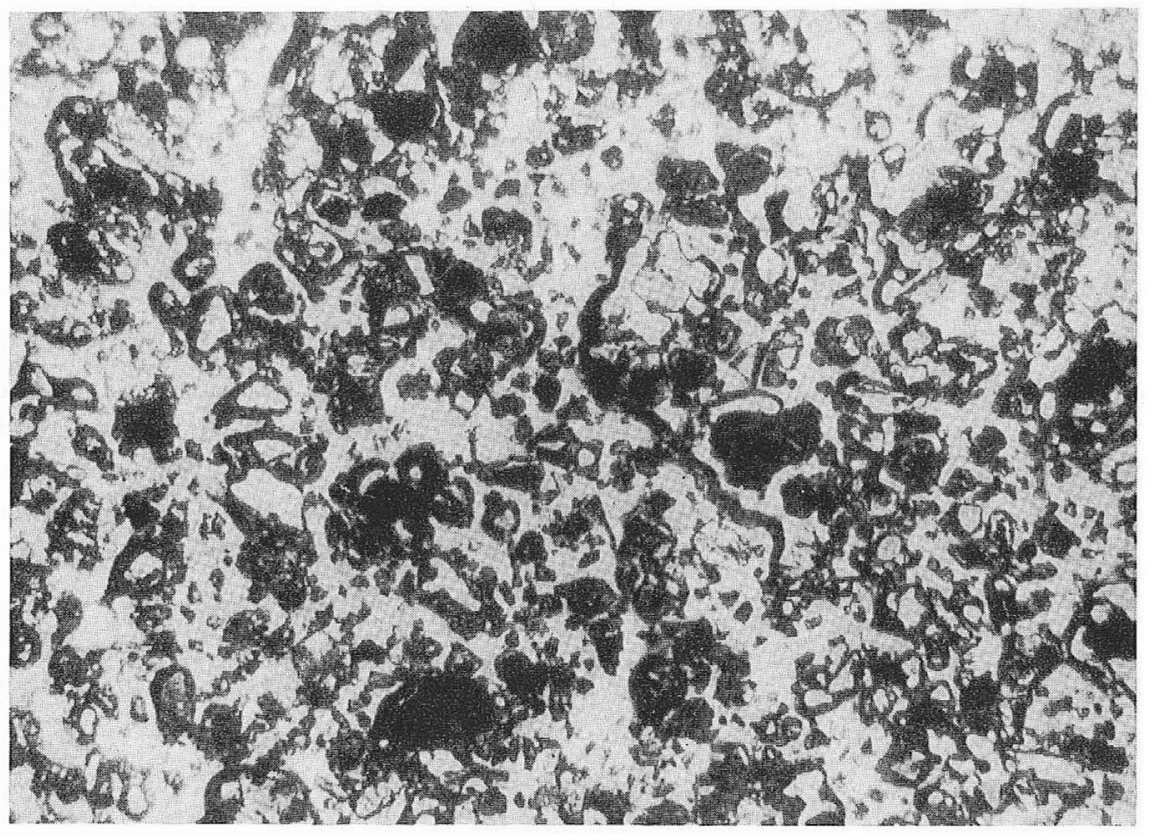

Fig. 6. Microscopic photograph of sand stuck on a vinyl tape. $z=102 \mathrm{~cm}$. 


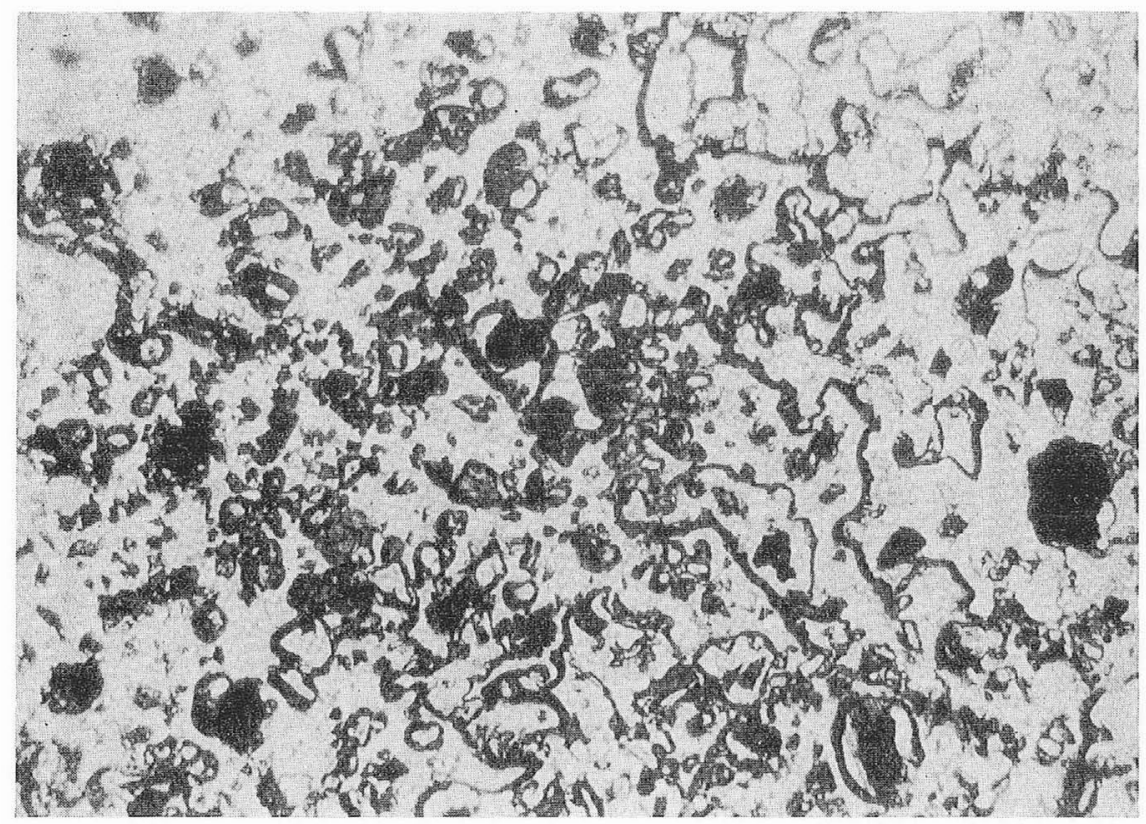

Fig. 7. Microscopic photograph of sand stuck on a vinyl tape. $z=200 \mathrm{~cm}$.

\subsection{Threshold friction velocity for saltation of sand $\left(u_{*: t)}\right)$}

The threshold wind velocity for sand shifting is usually related to, mainly,

i) the grain size of the sand,

ii) the water content of the sand,

and, further, to

iii) the stability of the air layer near the ground surface,

iv) humidity,

v) the sand structure and texture,

vi) the roughness of the sand surface,

vii) the settlement of grains on the sand surface,

viii) the temperature of the sand surface.

Thus it is evident that it is difficult to estimate the velocity exactly.

There have been various consideration about how to define the threshold wind velocity for saltation of sand, but here we define it in the following way: that is, we first count the number of cases where sand shifting has been recognized and the number of cases where it has not every 5 seconds for an observation period of 10 minutes, and simultaneously measure the vertical distribution of mean wind velocity for every 5 seconds. Then we define the threshold wind velocity for saltation of sand as a wind velocity for which the foregoing two numbers are equal.

The threshold wind velocities were obtained at each height. The vertical distribution of threshold wind velocities thus obtained is shown in Fig. 8. It will be seen from this figure that the logarithmic wind profile in the form of

$$
U_{t}=5.75 u_{*} \log \frac{z}{z_{0}}
$$




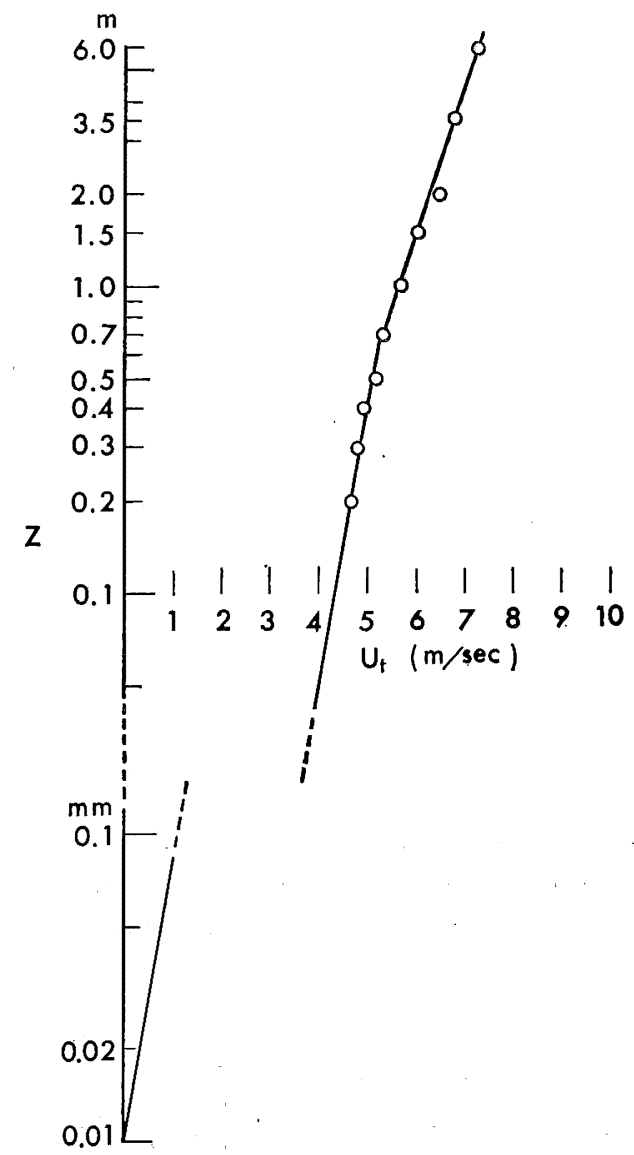

Fig. 8. Vertical distribution of the threshold wind velocity for saltation of sand. Observation time: 10 minutes.

may also hold for the layer lower than $70 \mathrm{~cm}$.

One of the most important factors which are related to making sand grains start to move may be considered to be the friction force $(\tau)$ by wind which acts directly on the sand grains at the surface, and since it is expressed as

$$
\tau=\rho u^{2} *
$$

then it may be estimated if a friction velocity $u_{*}$ can be found. Now when we obtain graphically a value of $u_{*}$ from this figure, this value means the threshold friction velocity for saltation of sand $u_{* t}$. In practice, $u_{* t}=20 \mathrm{~cm} / \mathrm{sec}$ can be obtained for $z_{0}=0.01 \mathrm{~mm}$ from this figure. On the other hand, from the empirical formula (3.1) which has been proposed by BAGNOLD,

$$
u_{* t}=18.5 \mathrm{~cm} / \mathrm{sec}
$$

can be obtained by using $\sigma=2.7 \mathrm{~g} / \mathrm{cm}^{2}, d=0.25 \mathrm{~mm}$ which have been found from actual measurements, and this value is somewhat smaller than that estimated from 


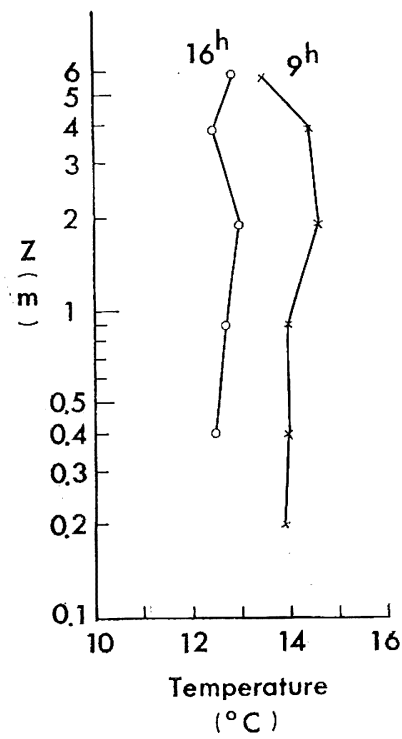

Fig. 9. Temperature profiles above the sand surface. Observation time: 10 minutes.

the threshold wind profile. The distribution of temperature with height in this case was in a neutral state as shown in Fig. 9, and the water content of the sand was $0 \%$, that is, the sand was in a perfectly dry state.

\subsection{Wind profile}

Wind profiles for various wind velocities are shown in Fig. 10. In this figure, the wind profile $A$ is that under a state where sand grains are not shifting, $B$ is that under a state where sand grains are starting to move and both $C$ and $D$ are those under a state where sand grains are shifting. As seen from this figure, every wind profile shows kink at a height of about $70 \mathrm{~cm}$. But, since the wind directly related to the sand movement is that in the layer very close to the ground surface, the wind velocity in the layer below $70 \mathrm{~cm}$ is dealt with. In the following, the case with shifting and that without shifting will be dealt with separately.

a) Wind profile in the case without sand shifting

The logarithmic law

$$
U=5.75 u_{*} \log \frac{z}{z_{0}}
$$

holds for the wind profile $A$. In this case the roughness parameter can be obtained graphically as

$$
z_{0}=0.012 \mathrm{~mm}
$$

from the figure. On the other hand, ZINGG (1952) has proposed the relation

$$
z_{0}=0.081 \log \frac{d}{0.18}
$$




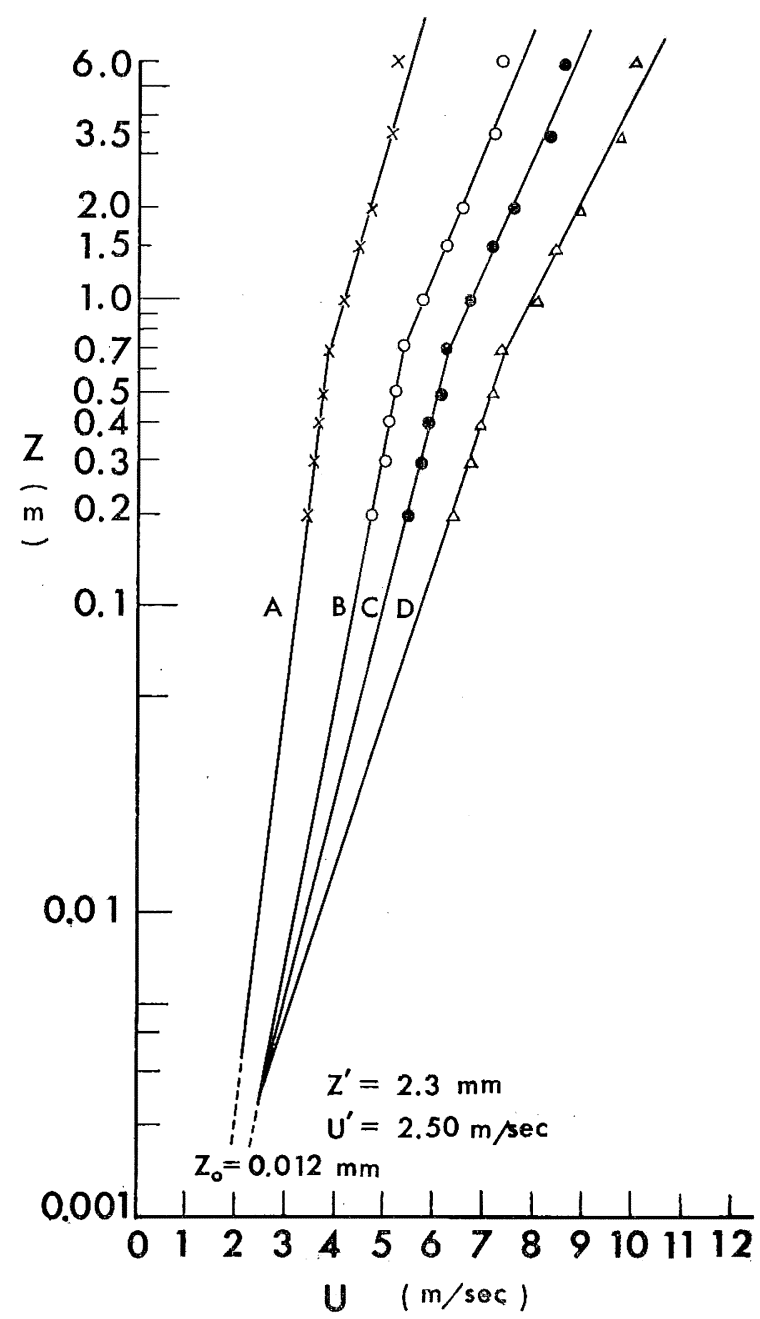

Fig. 10. Wind profiles above the sand surface. Observation time: 10 minutes.

between the roughness parameter $z_{0}$ and the gain diameter $d$. According to the observation $d=0.25 \mathrm{~mm}$, then $z_{0}$ can be estimated as

$$
z_{0}=0.0118 \mathrm{~mm}
$$

The agreement of both results is very satisfactory.

Furthermore, it seems that the value of $z_{0}$ in the case of wind profile $B$ where the sand grains are starting to move agrees with that of $z_{0}$ in the case of wind profile $A$ and the relation (5.2) can also be applied to this state, judging from the figure. Then $u_{*}$ can be obtained from the wind profile $B$ as

$$
u_{*}=19.6 \mathrm{~cm} / \mathrm{sec}
$$

and this may be considered to correspond to the threshold friction velocity for saltation $u_{* t}$. 
b) Wind profile in the case with sand shifting

Wind profiles $B, C$ and $D$ show those under the state of sand shifting. It will be seen from the figure that these wind profiles meet at a point. It seems that wind profiles meet at a point $z^{\prime}$ on the whole under the state of sand shifting. This phenomenon can be seen in the wind tunnel experiment by BELLY and also in BAGNOLD'S observation in the desert in Egypt.

The height of focus $z^{\prime}$ and the wind velocity there $U^{\prime}$ can be determined from the figure as

$$
\begin{aligned}
z^{\prime} & =2.3 \mathrm{~mm} \\
U^{\prime} & =2.50 \mathrm{~m} / \mathrm{sec}
\end{aligned}
$$

On the other hand, according to ZINGG, there are the relations (3.2) and (3.3) among $z^{\prime}, U^{\prime}$ and $d$. Hence inserting $d=0.25 \mathrm{~mm}$ (observed) into these relations we can obtain

$$
\begin{aligned}
z^{\prime} & =2.5 \mathrm{~mm} \\
U^{\prime} & =2.25 \mathrm{~m} / \mathrm{sec}
\end{aligned}
$$

Both show good agreement. The relation

$$
U=5.75 u_{*} \log \frac{z}{z^{\prime}}+U^{\prime}
$$

holds for $z \geqq z^{\prime}$.

Each value of $z^{\prime}, U^{\prime}$ and $u_{* t}$ estimated from wind tunnel experiments and field observations is shown in Table 1.

Table 1. Comparison of $z^{\prime}, U^{\prime}$ and $u_{* t}$ estimated from wind tunnel experiments and field observations

\begin{tabular}{l|c|c|c}
\hline \hline & $z^{\prime}(\mathrm{mm})$ & $U^{\prime}(\mathrm{m} / \mathrm{sec})$ & $u_{* t}(\mathrm{~cm} / \mathrm{sec})$ \\
\hline Wind tunnel (Bagnold) & 3 & 2.5 & \\
Desert in Egypt (Bagnold) & 10 & 4.0 & 23 \\
Anegasaki (Nemoto et $a l)$ & 2.3 & 2.5 & 20 \\
\hline
\end{tabular}

The values of $z^{\prime}$ and $U^{\prime}$ estimated in the desert by BAGNoLD are large compared with the others. BAGNOLD has stated, concerning this problem, that the large value of $z^{\prime}$ agrees with the fact that the amplitude of the ripple observed for the case of sand surface with various grain sizes increases, provided that $z$ ' is related to the amplitude of the ripple. But this problem must be gone into in future. It will be seen from the table that our results obtained at Anegasaki agree with those of BAGNOLD's wind-tunnel experiment.

\subsection{Relation between $U_{30}$ and $u_{*}$, and practical methods for estimation of threshold friction velocity}

BELLY has shown by wind tunnel experiment that there is a linear relation between mean wind velocity at a height of $30 \mathrm{~cm}, U_{30}$ and friction velocity $u_{*}$. This is 
clear from the fact that the relation (5.3) holds for $z \geqq z^{\prime}$, but this problem will be further discussed in the following.

Since $z_{0}, z^{\prime}$ and $U^{\prime}$ are each a function of grain diameter $d$, as seen from discussion thus far described, if $d$ is determined, $z_{0}, z^{\prime}$ and $U^{\prime}$ are all uniquely determined. Therefore, when $z$ is fixed at a certain height (here $z=30 \mathrm{~cm}$ ), the position and gradient of the two lines which show the relations between $U_{30}$ and $u_{*}$,

$$
\begin{aligned}
& U=5.75 u_{*} \log \frac{z}{z_{0}} \quad \text { (no sand shifting) } \\
& U=5.75 u_{*} \log \frac{z}{z_{0}}+U^{\prime} \text { (sand shifting) }
\end{aligned}
$$

are determined and $u_{* t}$ is also determined uniquely as a value at an intersecting point of the above-mentioned two lines. But this fact is valid for sand grains with diameters larger than $0.05 \mathrm{~mm}$.

Let us now show two examples of sand grains with diameters of $0.25 \mathrm{~mm}$ and $0.44 \mathrm{~mm}$, respectively.

1) The case of sand with a mean grain diameter of $0.25 \mathrm{~mm}$ (dune sand)

a) The case of no sand shifting

In this case, $z=30 \mathrm{~cm}$, and $z_{0}=0.012 \mathrm{~mm}$ as obtained from observation. Then by inserting these values into the relation (5.1), we can write it as

$$
U=5.75 u_{*} \log \left(\frac{30}{0.0012}\right)
$$

and this is shown by the line $A_{1}$ in Fig. 11.

b) The case of sand shifting

In this case, $z=30 \mathrm{~cm}$ and $z^{\prime}$ and $U^{\prime}$ are given as

$$
\begin{aligned}
z^{\prime} & =2.3 \mathrm{~mm} \\
U^{\prime} & =2.5 \mathrm{~m} / \mathrm{sec}
\end{aligned}
$$

by observation. Then by inserting these values into the relation (5.3), we can write it as

$$
U=5.75 \log \left(\frac{30}{0.23}\right)+2.5
$$

and this is shown by the line $A_{2}$ in the figure.

These two lines meet at a point as shown in the figure and the value of $u_{*}$ at this intersecting point is that of the threshold friction velocity. The threshold friction velocity $u_{* t}$ in this case can be estimated from the figure as

$$
u_{* \iota}=19.6 \mathrm{~cm} / \mathrm{sec}
$$

2) The case of sand with a mean grain diameter of $0.44 \mathrm{~mm}$ 


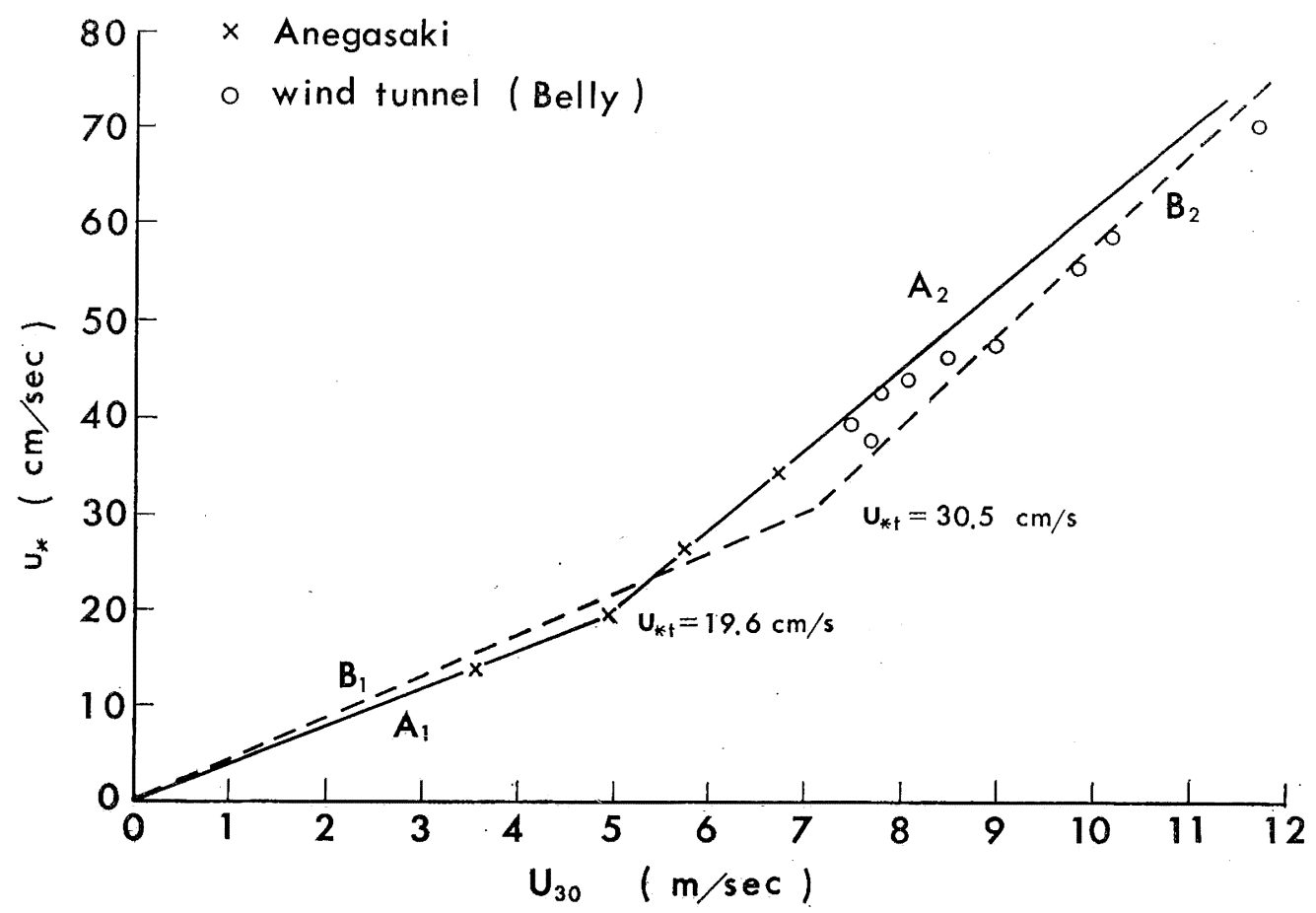

Fig. 11. Relation between wind velocity at a height of $30 \mathrm{~cm}$ above the sand surface $U_{30}$ and friction velocity $u_{*}$ for both case with sand shifting and that without sand shifting. $\mathrm{A}_{1}, \mathrm{~B}_{1}$ : no sand shifting, $\mathrm{A}_{2}, \mathrm{~B}_{2}$ : sand shifting.

a) The case of no sand shifting

In this case, $z=30 \mathrm{~cm}$ and the value of $z_{0}$ estimated from the relation (5.2) suggested by ZINGG is $0.31 \mathrm{~mm}$. Then by inserting these values into the relation (5.1), we can write it as

$$
U=5.75 u_{*} \log \left(\frac{30}{0.031}\right)
$$

and this is shown by the broken line $B_{1}$.

b) The case of sand shifting

In this case, $z=30 \mathrm{~cm}$ and $z^{\prime}$ and $U^{\prime}$ are estimated as

$$
\begin{aligned}
z^{\prime} & =4.3 \mathrm{~mm} \\
U^{\prime} & =3.9 \mathrm{~m} / \mathrm{sec}
\end{aligned}
$$

respectively, by using ZINGG's empirical formulas (3.2) and (3.3). Then by inserting these values into the relation (5.3), we can write it as

$$
U=5.75 u_{*} \log \left(\frac{30}{0.43}\right)+3.9
$$


and this is shown by the broken line $B_{2}$. Hence the threshold friction velocity can be obtained as

$$
u_{* t}=30.5 \mathrm{~cm} / \mathrm{sec}
$$

in the same way described above.

On the other hand, the values of $U_{30}$ and $u_{*}$ obtained at Anegasaki (denoted by $x$ ) are shown in the figure together with those obtained in the wind tunnel experiment by BELLY (denoted by $\mathrm{O}$ ).

Values of $u_{* t}$ obtained by different methods are summarized in Table 2.

Table 2. Values of $u_{*^{t}}$ obtained by different methods

\begin{tabular}{c|c|l}
\hline Grain dia. (mm) & $u_{* t}(\mathrm{~cm} / \mathrm{sec})$ & \multicolumn{1}{|c}{ Means of estimation } \\
\cline { 2 - 2 } 0.25 & 20 & threshold wind profile \\
& 19.6 & intersecting point \\
& 18.5 & Bagnold's empirical formula \\
\hline \multirow{3}{*}{0.44} & 30 & wind tunnel experiment \\
& 30.5 & intersecting point \\
& 34 & Bagnold's empirical formula \\
\hline
\end{tabular}

It will be seen from this table that these results on the whole agree with each other.

Then the following two methods will be suggested as practical for estimation of the threshold friction velocity in field observation.

1) The first method is one estimating $u_{* t}$ on the basis of wind profile observed in the field. That is, we plot the values of $u_{*}$ and $U$ at a fixed height which were obtained from wind profiles for various wind velocities (containing both cases of shifting and no shifting) on section paper as shown in Fig. 11. Then the threshold friction velocity can be obtained as a value of $u_{*}$ at an intersecting point of the two lines which show the relation between $U$ at a fixed height and $u_{*}$ for the case without sand shifting and that for the case with sand shifting.

2) The second method is one estimating $u_{* t}$ by calculation by making use of empirical formulas which have been proposed. That is, if a mean grain diameter is measured in the field, $z_{0}, z^{\prime}$ and $U^{\prime}$ will be determined by ZigG's empirical formulas. Then the threshold friction velocity can be obtained as a solution of simultaneous equations (5.1) and (5.3).

These methods are more simple and practical than that described in section 5.3, that is, the method using the threshold wind velocity profile. But it is to be noted that these methods are valid for the case sa isfying the conditions (i-v) described in chapter 3 .

\subsection{An example of estimation of the amount of sand transport} follows :

The amount of sand transport under critical conditions may be estimated as 
if

$$
\begin{aligned}
& C=1.5 \\
& d=D=0.25 \mathrm{~mm} \\
& \rho / g=1.25 \times 10^{-6} \text { c.g.s. } \\
& u_{*}=u_{* t}=20 \mathrm{~cm} / \mathrm{sec}
\end{aligned}
$$

we can obtain $Q$ as

$$
Q=0.015 \mathrm{~g} \mathrm{~cm}^{-1} \mathrm{sec}^{-1}
$$

by BAGNOLD's formula (3.5). Then the total amount of sand transported per unit width and per hour $Q_{\text {total }}$ may be estimated as

$$
\begin{aligned}
Q_{\text {total }} & =(\text { saltation })+(\text { surface creep }) \\
& =5.4+1.35 \\
& =6.75 \mathrm{~kg} \mathrm{~m}^{-1} \mathrm{hr}^{-1}
\end{aligned}
$$

including the amount of sand transport by surface creep. But this result has not been confirmed by observation.

\section{Summary}

The results may be summarized as follows:

1) It seems that the theoretical formula (2.2) on the amount of sand transport derived by KAWAMURA under stationary conditions is applicable to field observation in the layer very close the sand surface $(z \leqq 20 \mathrm{~cm})$.

2) The results which have been hitherto obtained are also applicable to field observation in the layer below $70 \mathrm{~cm}$ under the conditions of $(\mathrm{i}-\mathrm{v}$ ), that is,

i) wind profiles in field observation in the case of sand shiftng also meet at a point very close to the sand surface, that is, the existence of a focus can be confirmed,

ii) ZINGG's empirical formulas (3.2) and (3.3) on the height of focus and wind velocity there may also be applicable to field observation,

iii) ZiNGG's empirical formula (5.2) on the roughness parameter may also be applicable to field observation,

iv) BAGNOLD's empirical formula (3.1) on the threshold friction velocity seems to be applicable to field observation.

3) Two simple and practical methods for estimation of the threshold friction velocity $u_{* t}$ are suggested,

i) to estimate $u_{* t}$ as an intersecting point of the two lines which show, respectively, the relation between $U$ at a fixed height and $u_{*}$ for cases, without sand shifting and those with sand shifting,

ii) to estimate $u_{* t}$ by calculation by making use of empirical formulas already proposed, provided that the mean grain diameter is known.

Acknowledgement-The authors wish to express their sincere thanks to Messrs. Y. KAgeYAmA, J. YAMADA and T. KANBAYASHI, the Forestry Section of the Chiba Prefectural Office, and to Messrs. S. Akimoto, M. Miyake and T. Takatsu, the Japan Colored Steel Plate Co. Ltd., who have helped them in the survey. They must also thank Dr. S. ITo, the Japan Meteorological Agency, for his kind suggestion. 


\section{References}

Bagnold, R. A., 1936: The movement of desert sand. Proc. Roy. Soc. London, Series A, 15\%, $594-619$.

, 1937: The size grading of sand by wind. Proc. Roy. Soc. London, Series A, 163, 250-264.

1938: The measurement of sand storms. Proc. Roy. Soc. London, series A, 167, 282-291.

1954: The physics of blown sand and desert dunes. Methuen and Co., Ltd. London. $265 \mathrm{p}$.

Belly, Pierre-Yves, 1964: Sand movement by wind. Technical Memorandom 1, Univ. Calif., pp. 1-38 (including Addenda I, II, III).

ChepIL, W. S., 1945: Dynamics of wind erosion. Soil Science, 60, 305-320, 397-411, 475-480. KaWAmura, R., 1948: Sand movement by wind. Kagaku, 18, (11), 24-30 (in Japanese).

ZINGG, A. W., 1952: Wind tunnel studies of the movement of sedimentary material. Proc. of the Fifth Hydraulic Conference, 111-135.

\section{砂粒が跳躍し始める時の摩擦速度}

根本 茂, 三寺光雄, 高橋克旦, 魚津 博, 小林節子

京葉臨海工業地帯埋立地で行なった飛砂観測の結果を用いて，つぎの問題を検討した。

1）従来の理論的結果㧍よび風洞実験結果の野外観測への適用の可否。

2）砂粒が跳躍し始める時の摩擦速度 $\mathrm{u}_{* t}$ を決める簡単な実用的な方法。

その結果，

1）定常状態における飛砂量を推定する河村の理論式は砂面の極く近くでは野外観測に対しても適用でき ると思われる。

2)これまでに風洞実験でえられている結果は，限られた条件（i-v) のもとでは，野外锶測に対しても 適用できる，

i) 飛砂の場合には wind profiles は砂面に近いところで一点に集まる，すなわち，焦点 (focus) がある、

ii）焦点の高さ，焦点における風速に対して ZINGG の実験式が適用できる，

iii）砂粒の大きさから roughness parameter を決める Z Z INGG の実験式は野外観測にも適用でき る,

iv）砂粒が跳躍し始める時の摩摖速度を推定するBAGNOLD の笑験式は野外観測の場合にも適用で きそうである。

3） $\mathrm{u}_{* t}$ を決める簡単な実用的な方法を提案する,

i) wind profiles のみから求める方法,

ii）砂粒の平均粒径を測定し，あとは計算によって求める方法。 